\title{
Differential Inhibition of Invasion and Proliferation by Bisphosphonates: Anti-Metastatic Potential of Zoledronic Acid in Prostate Cancer
}

\author{
Richard Montague $^{\mathrm{a}}$, Claire A. Hart ${ }^{\mathrm{a}}$, Nicholas J. George ${ }^{\mathrm{a}, \mathrm{b}}$, Vijay A.C. Ramani ${ }^{\mathrm{a}, \mathrm{b}}$, \\ Michael D. Brown ${ }^{\mathrm{a}, 1}$, Noel W. Clarke ${ }^{\mathrm{a}, \mathrm{c}, 1, *}$ \\ ${ }^{a}$ Genito-Urinary Cancer Research Group, Kay Kendall Laboratory, Paterson Institute for Cancer Research, Christie Hospital NHS Trust, \\ Wilmslow Road, Manchester, M20 4BX, UK \\ ${ }^{\mathrm{b}}$ Department of Urology, Withington Hospital, Nell Lane, Manchester, UK \\ ${ }^{\mathrm{c}}$ Department of Urology, Salford Royal Hospital NHST, Stott Lane, Salford, UK \\ Accepted 1 April 2004
}

Available online 18 May 2004

\begin{abstract}
Objectives: To determine the mode of action of Zoledronic acid in the inhibition of metastasis in prostate cancer and the reduction of prostate cancer bone metastases.

Methods: Benign and malignant primary prostatic epithelial cells (PEC) and the PC-3 prostate cancer cell line were studied in co-culture using human bone marrow stroma in the presence of escalating doses of EDTA, Clodronate, Pamidronate and Zoledronic acid. PEC binding and colony growth in bone marrow stroma was measured using standardised quantitative techniques. PEC cellular invasion through Matrigel and an endothelial monolayer was measured either in invasion chambers or by the measurement of endothelial monolayer permeability to fluorescent dextran. Co-culture supernatants were assayed for specific cytokine levels. Bone marrow cellular toxicity was assessed using a standard Mix assay.

Results: Treatment of PEC with up to $100 \mu \mathrm{M}$ bisphosphonate did not affect their ability to bind to bone marrow endothelium or stroma. Bone marrow endothelial permeability was reduced by $100 \mu \mathrm{M}$ Zoledronic acid by $3.8 \%$ $(p=0.03856)$. Both Pamidronate $(40 \%$ at $100 \mu \mathrm{M}, p \leq 0.05)$ and Zoledronic acid inhibited PEC invasion, with Zoledronic acid being the most potent ( $40 \%$ at $10 \mu \mathrm{M}, p \leq 0.05$ rising to $91 \%$ at $100 \mu \mathrm{M}, p \leq 0.001$ ). Zoledronic acid inhibits malignant PEC proliferation in bone marrow stroma co-culture $(26.5 \%$ at $10 \mu \mathrm{M}$ rising to $66.5 \%$ at $40 \mu \mathrm{M})$. This was accompanied by changes within the cytokine milieu with a $>800 \%$ rise in TIMP- 2 .

Conclusion: Zoledronic acid is a potent inhibitor of PEC invasion across bone marrow endothelium and colony formation with the bone marrow stroma, affecting the MMP: TIMP-2 balance to favour MMP inhibition.

(C) 2004 Elsevier B.V. All rights reserved.
\end{abstract}

Keywords: Bisphosphonate; Zoledronic acid; Prostate cancer; Metastasis; Matrix metalloproteinase; TIMP-2

\section{Introduction}

Prostate cancer $(\mathrm{CaP})$ is the most common malignancy found in men. One in three of every male cancer

\footnotetext{
${ }^{*}$ Corresponding author. Tel. +44-161-4463232;

Fax: +44-161-4463033.

E-mail address: Noel.Clarke@christie-tr.nwest.nhs.uk (N.W. Clarke).

${ }^{1}$ Project was co-supervised by M.D. Brown and N.W. Clarke.
}

in America is of prostate origin [1] and in the UK alone there are over 24,700 new cases each year resulting in 10,000 deaths annually (Cancer Research UK Mortality Stats July 2001). Although prostate cells circulate widely in the peripheral circulation of men with advanced disease [2] metastatic deposits are not ubiquitous. When they occur, they tend to preferentially in to the red bone marrow [3]. The resulting bone metastases are present in $84 \%$ of men dying [4] from the 
disease and are directly responsible for considerable morbidity in the time to death [5], the median survival from presentation with bone metastases being 18 months [6].

In the red marrow the prostate epithelial cells bind rapidly to the bone marrow endothelium by an integrin mediated process [7]. Once bound, they migrate through the endothelial layer, following which, some of them go on to form metastases. The process by which this occurs is poorly understood but it is known to involve a combination of enhanced cell motility and degradation of the basement membrane by degradative enzymes such as matrix metalloproteinases (MMPs) [8].

Once through the endothelial cell layer the epithelial cells coalesce and proliferate as a metastatic colony in the marrow space, where they disturb local bone cellular function and displace the red marrow homeostasis to the extent that skeletal integrity and marrow function ultimately becomes compromised. This eventually manifests clinically as bone related morbidity, bone marrow failure and ultimately, the death of the individual.

The bisphosphonate class of drugs has been shown to be of therapeutic benefit in reducing skeletal morbidity from bone metastases in breast cancer [9] and more recently, Zoledronic acid, the most potent of this class of drugs has been proven to reduce morbid skeletal related events in prostate cancer [5]. This has been thought to be due to reduction in the osteoclast mediated bone resorption known to be associated with this disease $[10,11]$. However, an increasing number of reports have suggested that the later generation bisphosphonates containing an Imidazole ring have additional anti-metastatic and anti-cancer properties. The exact contribution of bone resorption inhibition vs. anticancer effects in the net reduction of skeletal morbidity by late generation bisphosphonates is unknown.

In vitro studies have demonstrated that the binding of breast and prostate cancer to bone surfaces is inhibited by Zoledronic acid [12] and the same group has suggested that this drug also has an inhibitory effect on cell proliferation. In experiments using prostate cancer cell lines a diminution in cellular migration was observed when cells were cultured with Zoledronic acid [13]. Similar effects have been noted with Zoledronic acid in breast cancer and it has been suggested that this mechanism is mediated by the effects of the drug acting on the cytoskeleton through a RhoA mediated mechanism and by inhibition of specific chemokines known to be involved in the development of bone metastases (such as stromal derived growth factor (SDF-1)) [14].
In addition to the anti-metastatic effects this class of drug has been shown to have a cytotoxic effect on the cancer cells themselves. In experiments in breast cancer Zoledronic acid was shown to promote apoptosis in in vitro [15-17] and further studies have now demonstrated this effect in prostate cancer $[18,19]$. The underlying mechanism of this effect remains to be determined but it may arise from inhibition of the mevalonate pathway. In an in vitro study using the prostate cancer cell line PC-3 and the nitrogen containing bisphosphonate Alendronate, the pro-apoptotic effects of the drug were arrested by competitive blockade of the inhibitory process using geranylgeranoil and farnesol, [20] a finding suggesting that in prostate cancer at least, the effect of the drug on the mevalonate pathway may be an important mechanism in the induction of apoptosis.

To establish the effects of nitrogen and non nitrogen containing bisphosphonates on the binding, migration and proliferation of human primary prostate epithelial cells, this study has utilised established methods for coculturing isolated human bone marrow stroma [21] and human bone marrow endothelium [7] with isolated human prostate epithelial cells from benign and malignant human prostate tissue in order to determine whether prostate cancer is affected by this class of drugs. By utilising specific cytokine assays and assays of MMPs and their inhibitors we have then gone on to study the induced changes in the cytokine milieu associated with the different types of bisphosphonate, in an effort to understand the mechanisms underpinning the observed effects in relation to binding, motility and growth in prostate cancer.

\section{Materials and methods}

\subsection{Materials}

All tissue culture plastics, cell culture inserts and Matrigel ${ }^{\mathbb{R}}$ Basement Membrane Matrix were obtained from Becton Dickinson Labware, NJ, USA. All general reagents including fibronectin were purchased from Sigma-Aldridge, Poole, UK. All tissue culture medium and horse serum (HS) was from Invitrogen, Paisley, UK with the exception of Ham's F12 media, PAA Laboratories, Austria and EBM-2 Bullet kit from Cambrex Bio Science Ltd., Berkshire, UK. Foetal calf serum (FCS) was supplied by Labtech International Ltd., Uckfield, East Sussex, UK. Worthington trypsin and collagenase type I was from Lorne Laboratories Ltd., Twyford, UK. ABTS buffer and tablets were from Roche Diagnostics Ltd., Sussex, UK. Erythropoietin (EPO) was a kind gift from Dr J Chang, Christie Hospital, Manchester, UK.

\subsection{Antibodies}

Mouse anti-human pan cytokeratin was obtained from SigmaAldridge, Poole, UK; rabbit anti-mouse biotinylated and HRP antibodies from DAKO Ltd., Cambridge, UK and Vectastain Elite 
ABC kit from Vector Laboratories, CA, USA. ELISA kits were supplied from R\&D Systems Europe Ltd., Abingdon, UK.

\subsection{Bisphosphonates}

Zoledronic acid, Pamidronate and Clodronate were a kind gift from Novartis Pharma, East Hampton, NJ, USA. Concentrations of drug were prepared in accordance to manufacturers guidelines and used in a range to incorporate therapeutic use.

\section{Methods}

\subsection{Tissue collection}

Human bone marrow stroma was obtained from volunteers undergoing surgery for benign disease. Briefly, cultures were grown to confluence by seeding at $2 \times 10^{6}$ cells $\mathrm{ml}^{-1}$ in long-term bone marrow culture medium (LTBCM) (Iscove's modified Dulbecco's medium at $350 \mathrm{mOsm}, 10 \%$ FCS, $10 \%$ HS, $5 \times 10^{-7} \mathrm{M}$ hydrocortisone). The cultures were grown at $33{ }^{\circ} \mathrm{C}$ in $5 \% \mathrm{CO}_{2}$ in air for $4-5$ weeks until haemopoietically active areas were observed [22].

Prostate tissue was obtained from men undergoing trans-urethral resection of the prostate. Informed consent was obtained and ethical committee approval granted. Individual chips were halved, half being sent for histological examination, the remainder used for tissue culture. Prostate epithelial cells were isolated using the method described by Lang et al. [21]. Briefly, prostate chips were digested in collagenase $\left(200 \mathrm{U} \mathrm{ml}^{-1}\right)$ and $0.1 \%(\mathrm{w} / \mathrm{v})$ trypsin to produce a single cell suspension. After a series of washes, epithelial cells were isolated from fibroblasts by a density centrifugation step.

\subsection{Cell lines}

The malignant prostate cell line PC-3 (bone marrow metastasis derived), [23] was cultured in HAMS-F12 media supplemented with $7 \%$ FCS and $2 \mathrm{mM}$ glutamine. Cultures were grown at $37{ }^{\circ} \mathrm{C}$ in a humidified atmosphere of $5 \% \mathrm{CO}_{2}$ in air.

The bone marrow endothelial cell line BMEC [24] was a kind gift from Dr Gracia Almeida-Porada (University of Nevada, Reno, NV, USA) and was cultured in EBM-2 Bullet kit/15\% FCS and $2 \mathrm{mM}$ L-Glutamine (EGM-2). BMEC flasks were pre-coated prior to cell culture by incubation at $37^{\circ} \mathrm{C}$ for 1 hour with $50 \mu \mathrm{g} / \mathrm{ml}$ of fibronectin in PBS. Cultures were grown at $37^{\circ} \mathrm{C}$ in a humidified atmosphere of $5 \% \mathrm{CO}_{2}$ in air and used up to passage 20 .

\subsection{Mix-CFC assay in methylcelluose}

Using the standard assay as described by Coutinho et al. [22] fresh human bone marrow mononuclear cells were isolated by density centrifugation and $2 \times 10^{5}$ cells were added to $30 \%$ FCS, $10 \% 5637$ bladder carcinoma cell line conditioned medium, $1 \%$ deionised BSA, $2 \mathrm{U} / \mathrm{ml}$ EPO and $1.35 \%$ methylcellulose together with varying concentrations of bisphosphonates. Assays were plated in triplicate, then incubated at $37{ }^{\circ} \mathrm{C}$ with $5 \% \mathrm{CO}_{2}$ and $5 \% \mathrm{O}_{2}$ for 14 days. The numbers of granulocyte/macrophage (GM-CFC) and erythroid (BFU-E) colonies in each well were counted using an inverted microscope.

\subsection{Permeability assay}

A variation of the assay described by Watts and Woodcock was used [25]. Briefly cell culture inserts $(1 \mu \mathrm{m}$ pore size $)$ were coated with fibronectin $(50 \mu \mathrm{g} /$ $\mathrm{ml}$ ) and seeded with the BMEC cell line. These were cultured until tight cell junctions were formed. Once established $1 \mathrm{ml}$ EGM-2 media was added to the abluminal (well) chamber of a 24 well plate, and $0.2 \mathrm{ml}$ EGM-2 together with $100 \mu \mathrm{M}$ of bisphosphonate to the luminal (insert) chamber, each test was carried out in duplicate. Three sets of controls were used, blank containing an insert with no BMEC cell line established, negative control with only BMEC present and no test drug added and a positive control being BMEC cells incubated with $0.5 \%$ trypsin. After incubation of $1 \mathrm{~h}$ at $37^{\circ} \mathrm{C}, 16 \mu \mathrm{l}$ of fluorescent dextran $(10 \mathrm{mg} / \mathrm{ml}$, mol.wt. 40,000) was added to the luminal chamber and incubated for a further 30 minutes. The inserts were removed and scanned using a Biolite FC500 fluorescence plate reader together with a serial dilution of F-dextran to form a standard curve. Percentage permeability of each monolayer was calculated from the standard curve, normalised to the media control ( $0 \%$ permeability) and the trypsin control ( $100 \%$ permeability) and expressed as percentage endothelial monolayer permeability.

\subsection{Binding assay}

Using the method described by Scott et al. [7] the BMEC cell line or human bone marrow stroma were seeded into 96 well plates, tissue culture plastic (TCP) alone was used as a control. Once established, $5 \times 10^{4}$ PC-3 cells/well were added in HAMS-F12: LTBCM $(1: 1, \mathrm{v}: \mathrm{v})$ together with varying concentrations of bisphosphonates. Binding was allowed to take place over a 1 or $24 \mathrm{hr}$ period at $37{ }^{\circ} \mathrm{C}$ after which any unbound cells were removed and the plate fixed with methanol:acetone $(1: 1, \mathrm{v}: \mathrm{v})$. Plates were blocked with $20 \%$ rabbit serum then $3 \% \mathrm{H}_{2} \mathrm{O}_{2}$ and labelled with a pan-cytokeratin antibody diluted 1:3200 (v:v) followed by an anti-mouse HRP antibody (1:400). Finally, the plates were washed with $\mathrm{PBS}$, then $\mathrm{dH}_{2} \mathrm{O}$ and once 
with the ABTS buffer. ABTS (2,2'-Azino-di-[3-ethylbenzthiazoline sulfonate (6)] diammonium salt crystals) solution (substrate for horse radish peroxidase) was prepared according to manufacturers instructions, added to the plate and allowed to develop for $45 \mathrm{~min}$ utes. Optical density was read at $405 \mathrm{~nm}$ on an ELISA plate reader.

\subsection{Invasion assay}

Cell culture inserts $(8 \mu \mathrm{m}$ pore size) were coated with Matrigel diluted 1:25 (v:v) with DMEM and incubated for $2 \mathrm{hr}$ at $37{ }^{\circ} \mathrm{C}$. The inserts were placed in a 24 well plate containing $1 \mathrm{ml}$ of DMEM/0.1\% BSA with TCP, BMS or BMEC at the base. PC-3 cells $\left(1 \times 10^{5}\right.$ cells in $0.5 \mathrm{ml}$ of DMEM/0.1\% BSA $)$ were seeded into the top of the inserts together with varying concentrations of bisphosphonates. The cells were incubated at $37{ }^{\circ} \mathrm{C}$ for $18 \mathrm{hr}$, after which the inserts were removed, washed in PBS and the non-invading cells together with the Matrigel removed from the top of the insert by wiping with a cotton bud. The inserts were fixed and stained in $2 \%$ crystal violet $/ 20 \%$ methanol and left to air dry. Cells on the bottom of the insert were counted according to manufacturer's instructions. Each experiment was carried out in duplicate.

Alternatively, an endothelial barrier was formed using Matrigel as a base in the insert with a confluent layer of BMEC cells on top. For this assay inserts were fixed in methanol:acetone (1:1, v:v) for $20 \mathrm{~min}$ instead of fixing in crystal violet. Inserts were stained for cytokeratin by immunocytochemistry to distinguish between the numbers of epithelial cells that had invaded compared to endothelial cells.

\subsection{Inhibition assay}

Using the method described by Hart et al. [8] BMS was seeded and grown to confluence in 24 well plates. Primary prostatic epithelial cells were added at a concentration of $1 \times 10^{4} \mathrm{ml}^{-1}$ in KeratinocyteSFM:LTBCM (3:1, v:v). Bisphosphonates were added at differing concentrations and the co-culture left for 72 hours at $37{ }^{\circ} \mathrm{C}$ in $5 \% \mathrm{CO}_{2}$ and air before being fixed with methanol: acetone $(1: 1, \mathrm{v}: \mathrm{v})$. These cultures were labelled for cytokeratin using immunohistochemistry. Briefly, cultures were incubated with mouse antihuman pan cytokeratin 1:200 for $2 \mathrm{hr}$ at room temperature after blocking with $10 \%$ rabbit serum then $0.3 \%$ hydrogen peroxide. This was followed by addition of biotinylated rabbit anti-mouse 1:400 for $40 \mathrm{~min}$ at room temperature. A complex of avidin $\mathrm{DH}$ and biotinylated horseradish peroxidase $\mathrm{H}$ (Vectastain Elite ABC kit) was added for 15-20 min, followed by the addition of DAB substrate for 5-10 min. Resulting colonies were quantified both numerically and in terms of area by measuring with an eyepiece graticule. The experiment was carried out in duplicate and replicated 4 times using benign or malignant prostate epithelial cells.

\subsection{ELISA}

Supernatants from the inhibition assay cultures (method described above) were collected during their removal to allow fixation of the culture at $72 \mathrm{hr}$. This media was centrifuged to remove any cell debris, then frozen in $200 \mu \mathrm{l}$ aliquots at $-80{ }^{\circ} \mathrm{C}$. The test supernatants were defrosted together and run on R\&D Systems ELISA kits according to manufacturer's protocols.

\section{Results}

\subsection{Therapeutic window determination for zoledronic acid}

The in vitro therapeutic window for Zoledronic acid was assessed based on the observation that in clinical studies with Zoledronic acid patients treated with the drug have a lower level of haemoglobin by comparison with controls [5]. We therefore used this clinical observation to determine the dose range for our in vitro study. The effect of Zoledronic acid, Pamidronate, Clodronate and EDTA on haemopoietic progenitors was assessed via the mixed assay described by Coutinho et al. [22]. Haemopoietic progenitors isolated from fresh human bone marrow were seeded at $2 \times 10^{5}$ cells per well in the presence of $1.35 \%$ methycellulose, conditioned media and varying concentrations of bisphosphonate or EDTA $(0-200 \mu \mathrm{M})$. The number of granulocyte/macrophage colonies (GM-CFC) and erythroid colonies (BFU-E) were counted 14 days post exposure to bisphosphonate.

Fig. 1a shows the total number of colonies formed in the presence of varying concentrations of EDTA, Clodronate, Pamidronate and Zoledronic acid. EDTA, Pamidronate and Clodronate had no effect on the ability of haemopoietic progenitors to generate GMCSF of BFU-E colonies within the range $(0-200 \mu \mathrm{M})$ tested. Zoledronic acid significantly reduced the numbers of colonies formed in the assay at concentrations above $100 \mu \mathrm{M}$ resulting in an almost complete inhibition of colony formation. The effect of Zoledronic acid on the types of colonies formed is shown in Fig. $1 \mathrm{~b}$ (BFU-E) and Fig. 1c (GM-CFC). Concentrations above $50 \mu \mathrm{M}$ almost completely inhibit the formation of the erythroid BFU-E colonies with only $2.25 \pm 1.5$ colonies being generated in the presence of $50 \mu \mathrm{M}$. The effect is less marked on the formation of GM-CFC 

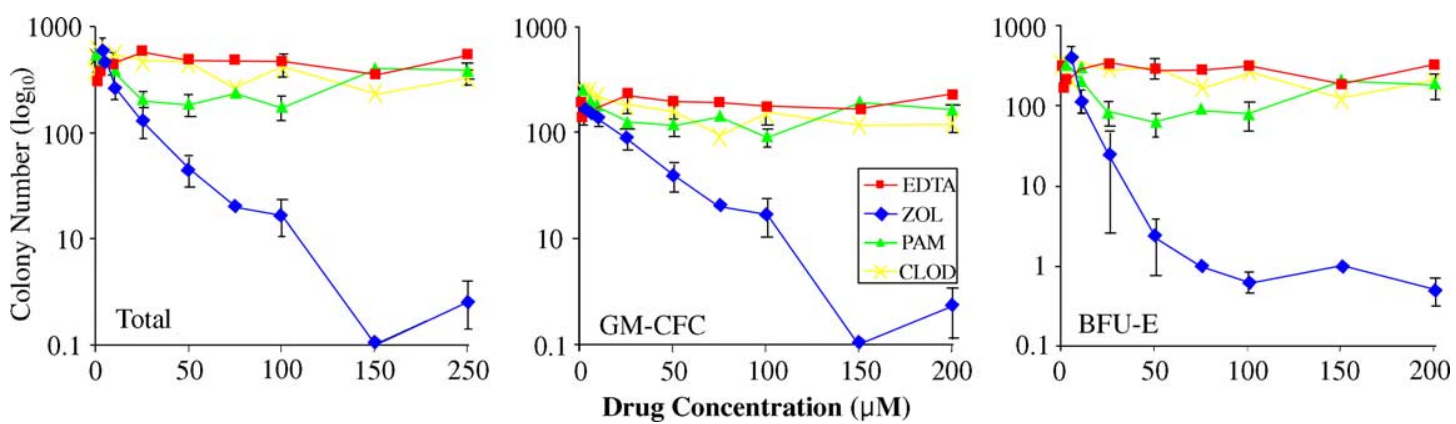

Fig. 1. Effect of bisphosphonate treatment on haematopoietic progenitors. Freshly isolated human bone marrow mononuclear cells were plated at $2 \times 10^{5}$ cells per well in the presence of varying concentrations of Zoledronic acid (Zol), Pamidronate (Pam), Clodronate (Clod) or EDTA in triplicate. After 14 days at $37{ }^{\circ} \mathrm{C}, 5 \% \mathrm{CO}_{2}$ the total number of colonies formed (a), granulocyte/macrophage (GM-CFC) colonies (b) and erythroid (BFU-E) colonies (c) were counted using an inverted microscope.

colonies, $16.9 \pm 6.6$ colonies at $100 \mu \mathrm{M}$. At concentrations of $150 \mu \mathrm{M}$ and above Zoledronic acid completely inhibited the formation of GM-CFC colonies.

\subsection{Effect of zoledronic acid on PC-3 binding to bone marrow endothelial cells}

Metastatic prostate epithelial cells after entering the blood circulation preferentially bind to the bone marrow endothelium. Therefore the effect of Zoledronic acid on the binding characteristics of prostate epithelial cells to bone marrow endothelium was determined using the method described by Scott et al. [7]. In the presence of varying concentrations of bisphosphonate or EDTA, PC-3 cells were allowed to bind to a confluent bone marrow endothelial cell monolayer for either $1 \mathrm{hr}$ (Fig. 2a) or $24 \mathrm{hr}$ (Fig. 2b) prior to staining and the optical density at $405 \mathrm{~nm}$ determined.

Fig. 2 shows that incubation with either concentrations of up to $100 \mu \mathrm{M}$ Zoledronic acid, Pamidronate, Clodronate or EDTA for up to $24 \mathrm{hr}$ had no significant $(p \geq 0.05)$ effect on the binding of PC-3 prostate epithelial cells to the bone marrow endothelial (BMEC) monolayer.

\subsection{Effect of zoledronic acid on bone marrow endothelial monolayer permeability}

For prostate epithelial cell to form colonies within the bone marrow stroma they must escape from the vasculature by invading through the bone marrow endothelium. To determine the effect that bisphosphonates may have on this endothelial layer a 'Permeability Assay' was used. This utilised migration of fluorescent dextran across a confluent bone marrow endothelial layer (BMEC), any alteration in the confluent endothelial layer would result in increases in the amount of F-dextran detected the other side.

The amount of F-dextran was determined from a standard curve and the data normalised to the negative media only control and the positive trypsin control. Table 1 shows the effect of $100 \mu \mathrm{M}$ bisphosphonate or EDTA on the BMEC monolayer permeability. Only incubation with $100 \mu \mathrm{M}$ EDTA resulted in a significant $(p=0.00667)$ increase in BMEC monolayer permeability $(2.95 \%)$. Both Pamidronate and Clodronate had no significant effect on the permeability of the BMEC monolayer $(p \geq 0.05)$. Incubation with Zoledronic acid below concentrations of $100 \mu \mathrm{M}$ had no significant effect on BMEC permeability. Incubation with $100 \mu \mathrm{M}$ Zoledronic acid resulted in a small but significant $(p=0.03856)$ reduction in permeability as compared to the media only control $(-3.80 \%)$.

\subsection{Effect of zoledronic acid on PC-3 invasion through the bone marrow endothelium}

We have previously shown that malignant prostate epithelial cells can invade through a synthetic basement membrane, Matrigel in response to stimuli from bone marrow stoma [7]. To determine the effect of Zoledronic acid and other bisphosphonates upon the ability of malignant cells to invade through a basement membrane, $1 \times 10^{5}$ PC- 3 cells were loaded on Matrigel gel coated, $8 \mu \mathrm{M}$ pore invasion chambers in the presence of varying concentrations of bisphosphonate

\section{Table 1}

Percentage permeability of bone marrow endothelial cell monolayer (BMEC) post incubation with $100 \mu \mathrm{M}$ EDTA or bisphosphonate

\begin{tabular}{lcl}
\hline Condition & $\begin{array}{l}\text { Average percentage } \\
\text { permeability }\end{array}$ & $\begin{array}{l}\text { Standard } \\
\text { error }\end{array}$ \\
\hline EDTA & 2.94 & 0.89 \\
Zoledronic acid & -3.80 & 1.72 \\
Pamidronate & -0.57 & 0.13 \\
Clodronate & -0.69 & 0.59 \\
\hline
\end{tabular}

Amount of F-dextran crossing the bone marrow endothelial layer was determined from a standard curve prior to the data normalised to the negative media control $(0 \%)$ and positive trypsin control $(100 \%)$. 

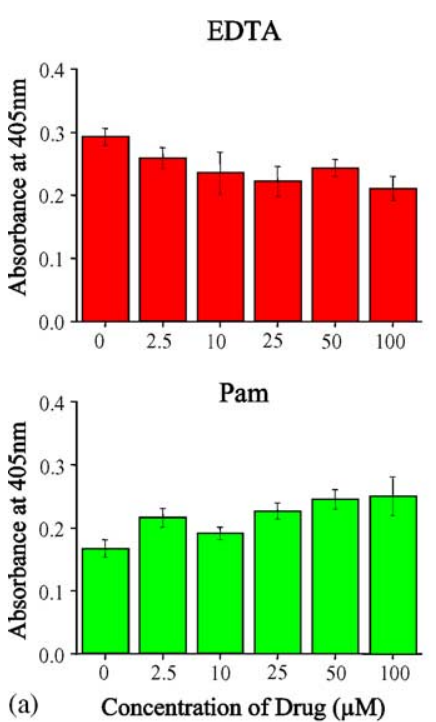

EDTA
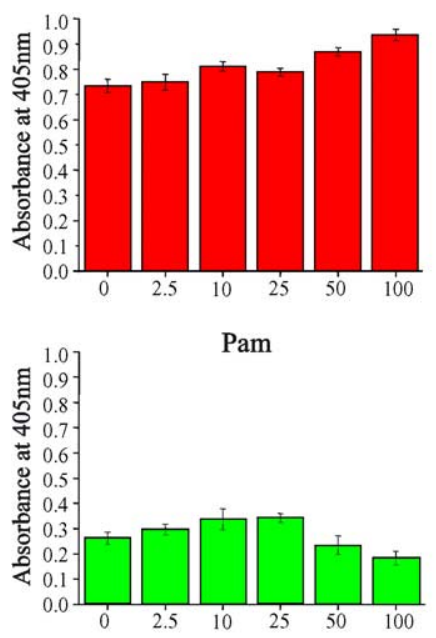

(b) Concentration of Drug $(\mu \mathrm{M})$
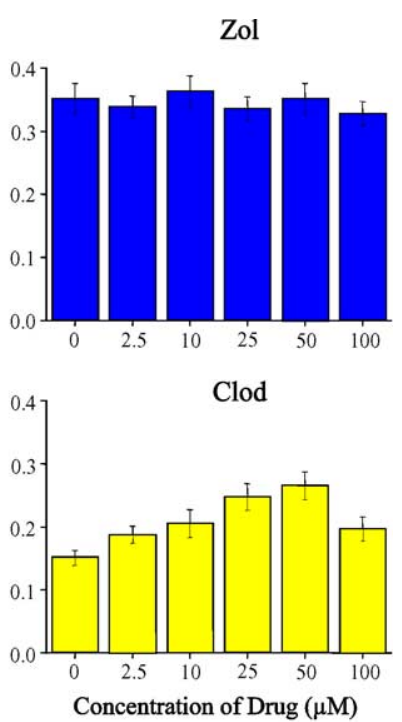

Zol
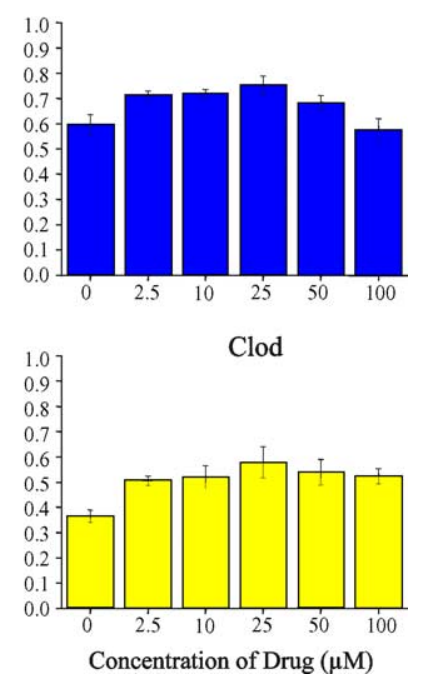

Fig. 2. Effect of bisphosphonate treatment on the binding of prostate epithelial cells to bone marrow endothelium. In a 96 well format $5 \times 10^{4}$ PC-3 cells were seeded on to confluent bone marrow endothelial cells in the presence of varying concentration of Zoledronic acid (Zol), Pamidronate (Pam), Clodronate (Clod) or EDTA. After incubation at $37{ }^{\circ} \mathrm{C} 5 \% \mathrm{CO}_{2}$ for either 1 (a) or $24 \mathrm{hr}$ (b) the well were washed and bound epithelial cells labelled with anti pan cytokeratin primary and anti mouse HRP secondary antibody. Degree of binding was determined by measuring the optical density at $405 \mathrm{~nm}$. There was no significant effect seen from any of the bisphosphonates.

or EDTA and the number of invasive cells, in response to bone marrow stroma, counted and compared to the number of invasive cells in the absence of bisphosphonate (Fig. 3a). EDTA and Clodronate had no effect on the ability of PC-3 to invade through Matrigel, even at a concentration of $100 \mu \mathrm{M}$. Both Pamidronate and Zoledronic acid reduced the invasive ability of PC-3 cells in response to bone marrow stroma, with the greatest affect being observed with Zoledronic acid. Concentration of Pamidronate of $25 \mu \mathrm{M}$ resulted in a
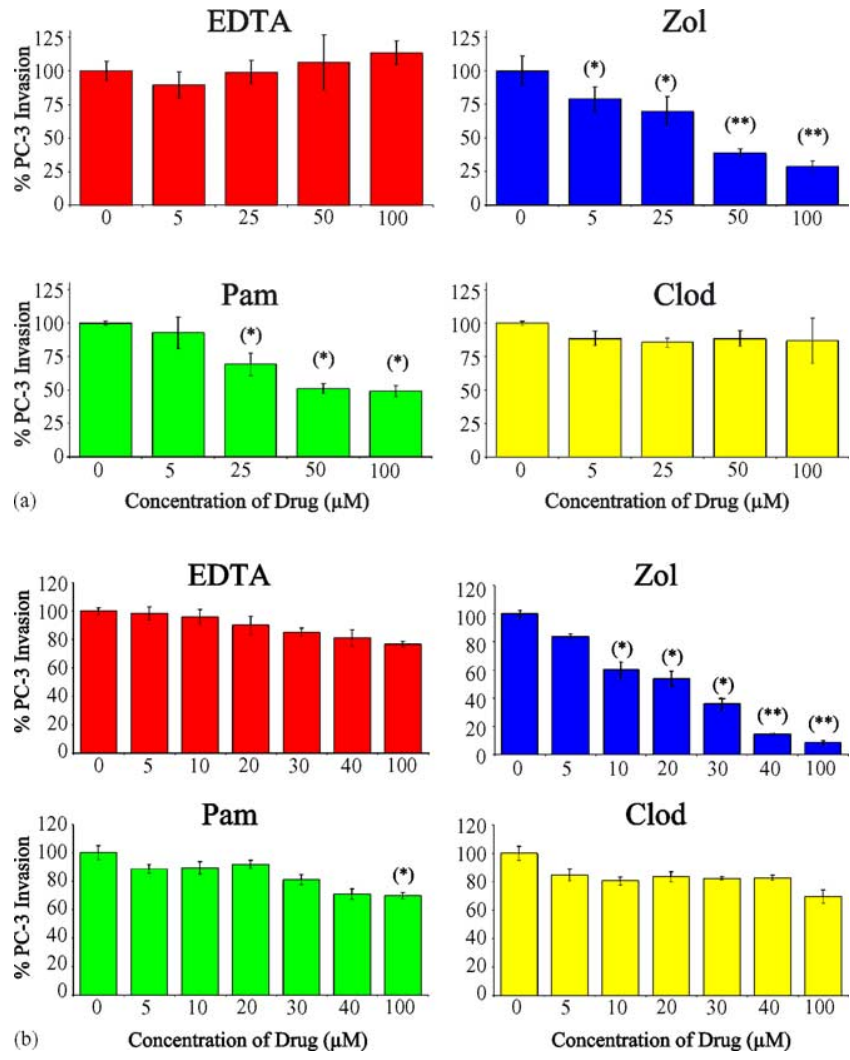

Fig. 3. Effect of bisphosphonate treatment on the invasive capacity of the prostate epithelial cell line PC-3. Cell culture inserts ( $8 \mu \mathrm{m}$ pore size), which were coated with either Matrigel alone (a) or a Matrigel layer covered with a confluent layer of BMECs (b) were placed in 24 well plates containing confluent layers of BMECs, primary human bone marrow stroma or tissue culture media. The inserts were seeded with PC-3 cells at $1 \times 10^{5}$ cells per insert in the presence of varying concentrations of Zoledronic acid (Zol), Pamidronate (Pam), Clodronate (Clod) or EDTA. The number of PC-3 cells that had invaded through each layer at each concentration of drug was determined $18 \mathrm{~h}$ post seeding. ${ }^{*} p<0.05$ and ${ }^{* *} p<0.005$ (compared to untreated control).

significant decrease in invasion of $31 \%(p<0.05)$ and a maximal decrease in invasion of $51 \%$ at $100 \mu \mathrm{M}$.

Zoledronic acid had a more potent effect on PC-3 invasion through Matrigel with an effect being observed at a concentration of $5 \mu \mathrm{M}$, resulting in a decrease in invasion of $30 \%(p=0.016)$. The effect of Zoledronic acid increases with increasing concentration with a maximal effect at $100 \mu \mathrm{M}$ in which a reduction of $71 \%(p=0.003)$ was observed.

We increased the complexity of this in vitro model of invasion more closely to mimic the invasion process from the vasculature to the bone marrow stroma by including a bone marrow endothelium above the basement membrane. The $8 \mu \mathrm{m}$ invasion chamber was coated with a Matrigel basement membrane, which supported a confluent bone marrow endothelial (BMEC) layer (Hart et al. manuscript in preparation). Clodronate and EDTA had no effect on the ability of 
PC-3 to invade through a bone marrow endothelial cell layer and a basement membrane. Unlike the previous model treatment with concentrations of Pamidronate below $40 \mu \mathrm{M}$ had no effect on the invasive capability of PC-3 cells. The effect of higher concentrations of Pamidronate reduced invasion but there was only a $30 \%$ reduction in invasion at $100 \mu \mathrm{M}$ by comparison with $51 \%$ in the basement membrane only model.

Treatment with Zoledronic acid resulted in a significant reduction in PC-3 invasion. Unlike the basement membrane model there was no significant reduction in invasion observed with $5 \mu \mathrm{M}$ Zoledronic acid. Above this concentration Zoledronic acid had a marked effect, greater than that seen in the basement membrane model, on the invasive ability of PC-3 cells with a $40 \%$ reduction at $10 \mu \mathrm{M}$ concentration ( $p=0.0136)$, increasing to $85 \%$ inhibition $(p<0.001)$ at $40 \mu \mathrm{M}$ and $91 \%$ $(p<0.001)$ at $100 \mu \mathrm{M}$ (Fig. 3b).

\subsection{Effect of zoledronic acid on PC-3 colony formation in bone marrow stroma co-culture}

Following invasion of the bone marrow endothelium malignant prostate epithelial cells must first bind to the bone marrow stroma and then proliferate to form a metastatic colony. The effect of varying concentrations of bisphosphonate and EDTA on the ability of PC-3 cells to bind to confluent primary human bone marrow stroma within either a $1 \mathrm{hr}$ (Fig. 4a) or $24 \mathrm{hr}$ (Fig. 4b) period was assessed. Bisphosphonates and EDTA do not have any effect on the ability of PC-3 cells to bind to bone marrow stroma accept at $100 \mu \mathrm{M}$ concentrations of Zoledronic acid, which reduce the amount of binding within the first hour of incubation by $28.76 \%$ ( $p=0.006$ ) (Fig. 4a). This concentration of Zoledronic acid did not however result in an overall reduction in binding to bone marrow stroma over a 24 hour period (Fig. 4b).

The effect of Zoledronic acid on the ability of prostate epithelial cells to generate colonies within a bone marrow stroma co-culture is shown in Fig. 5. We have previously shown that both non-malignant and malignant prostate epithelial cells grow preferentially within the bone marrow stroma [21]. We therefore cocultured both non-malignant and malignant primary prostate epithelial cells with primary human bone marrow stroma in the presence of varying concentration of bisphosphonate or EDTA. Colonies were stained, counted and measured $72 \mathrm{hr}$ post inoculation of the bone marrow stroma with the prostate epithelial cells. The average colony size for each concentration of bisphosphonate was then compared to prostate epithelial colony size co-cultured in the absence of bisphosphonate. Both EDTA and Clodronate did not
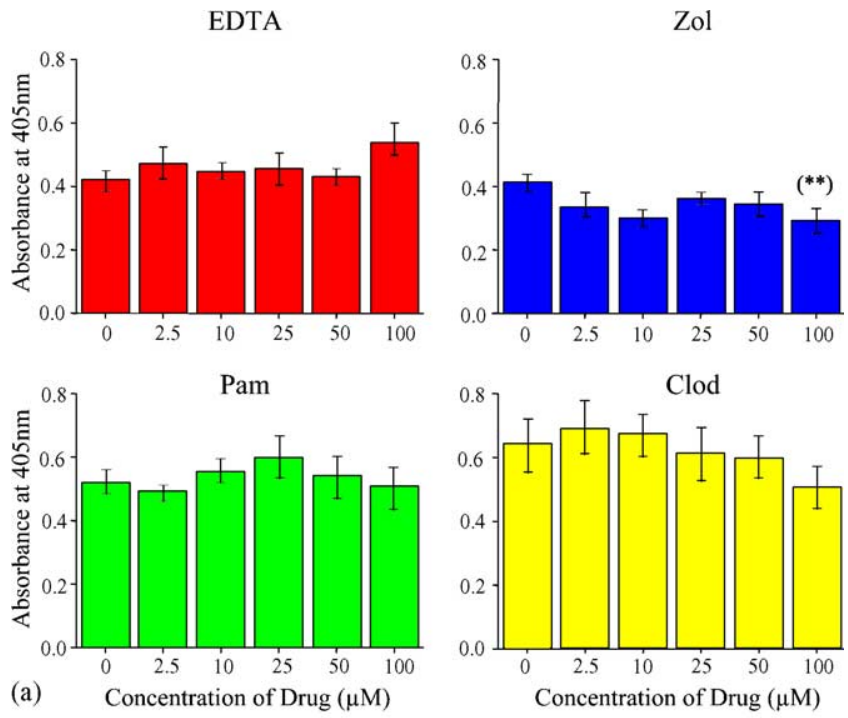

EDTA
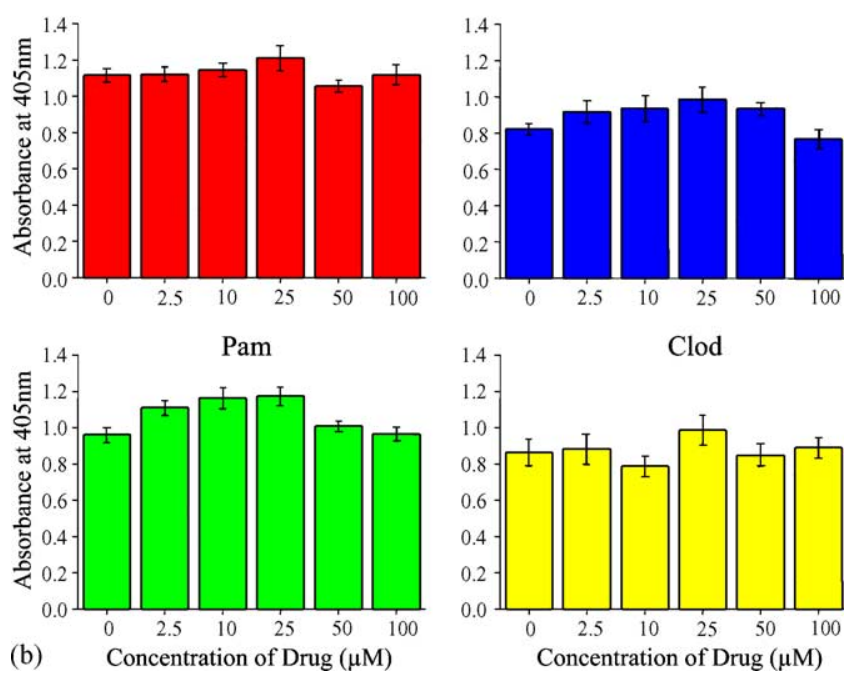

Fig. 4. Effect of bisphosphonate treatment on the binding of prostate epithelial cells to primary human bone marrow stroma. In a 96 well format $5 \times 10^{4}$ PC-3 cells were seeded on to confluent primary human bone marrow stroma in the presence of varying concentration of Zoledronic acid (Zol), Pamidronate (Pam), Clodronate (Clod) or EDTA. After incubation at $37{ }^{\circ} \mathrm{C} 5 \% \mathrm{CO}_{2}$ for either 1 (a) or $24 \mathrm{hr}$ (b) the well were washed and bound epithelial cells labelled with anti pan cytokeratin primary and anti mouse HRP secondary antibody. Degree of binding was determined by measuring the optical density at $405 \mathrm{~nm}^{* *} p<0.005$ (compared to untreated control).

significantly affect the non-malignant (Fig. 5a) or malignant (Fig. 5b) colony sizes at concentrations of up to $40 \mu \mathrm{M}$.

Both Pamidronate and Zoledronic acid reduced the prostate epithelial colony size in co-culture, with Zoledronic acid showing the greatest effect. A significant decrease in non-malignant colony size was observed with concentration of Pamidronate $\geq 30 \mu \mathrm{M}$, with a $14 \%$ and $21 \%$ reduction at $30 \mu \mathrm{M}$ and $40 \mu \mathrm{M}$ respectively. This effect was also observed with co-cultures 

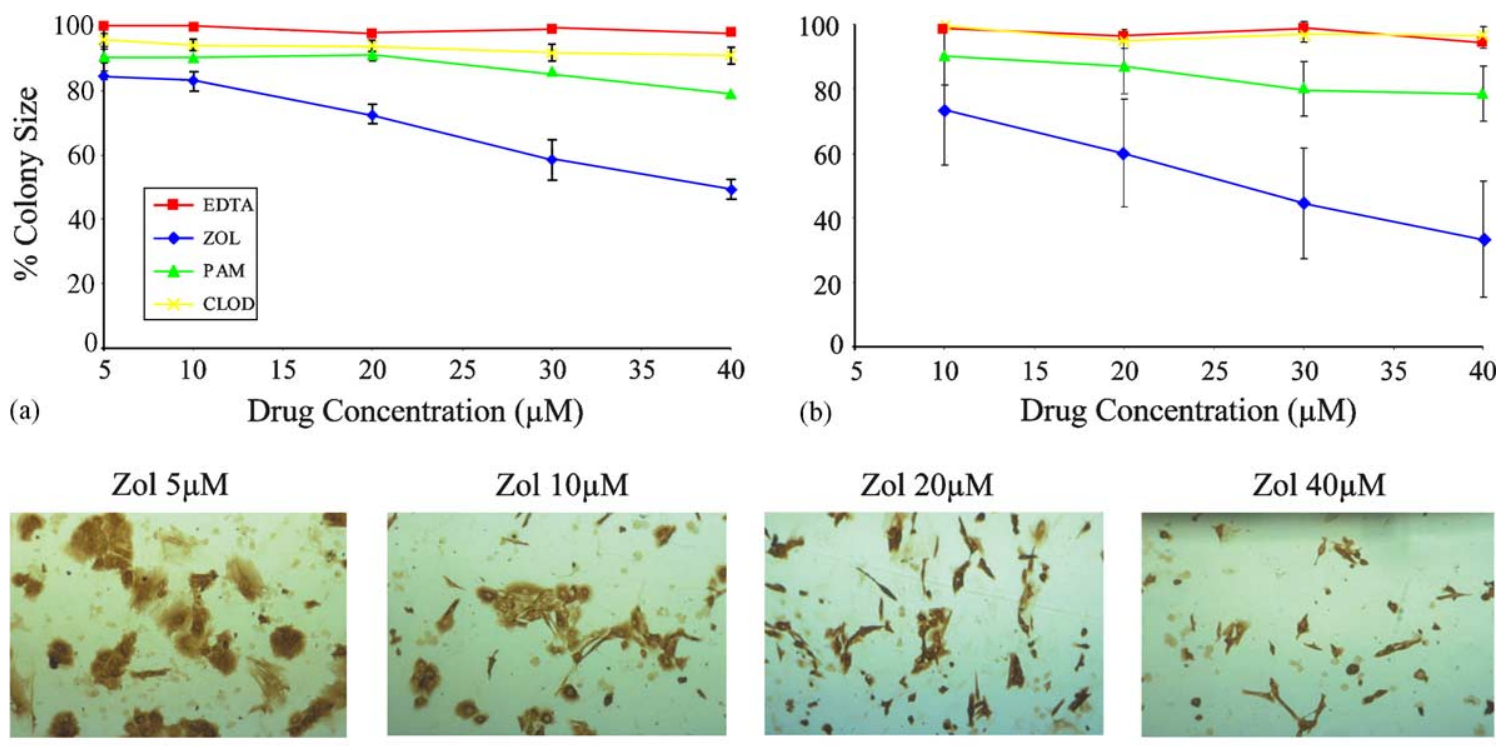

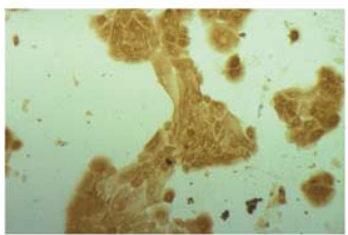

(c) Control

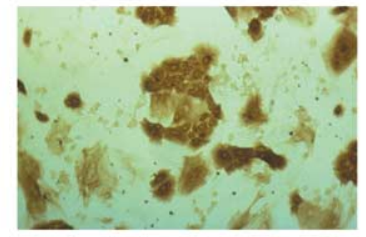

EDTA $40 \mu \mathrm{M}$

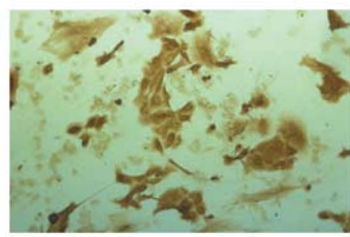

Pam $40 \mu \mathrm{M}$

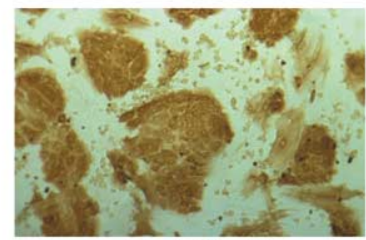

Clod $40 \mu \mathrm{M}$

Fig. 5. Effect of bisphosphonate treatment on prostate epithelial colony formation in primary human bone marrow co-culture. Confluent primary human bone marrow stroma was seeded with $1 \times 10^{4}$ primary benign (a) or malignant prostate epithelial cells in the presence of varying concentrations of Zoledronic acid (Zol), Pamidronate (Pam), Clodronate (Clod) or EDTA. Co-Cultures were fixed $72 \mathrm{hr}$ post seeding and prostate epithelial colonies visualised by cytokeratin staining $(n=4)$. (c) Photomicrographs of representative prostate epithelial colonies grown in the presence of 5, 10, 20 and $40 \mu \mathrm{M}$ Zoledronic acid (Zol), $40 \mu \mathrm{M}$ Pamidronate (Pam), Clodronate (Clod) and a no drug control. Inhibition was seen with Pamidronate and Zoledronic acid but there was greater inhibition with the latter compound.

containing malignant epithelial cells. The reduction in colony size was greater and occurred at lower concentrations of Zoledronic acid. Concentrations of $10 \mu \mathrm{M}$ Zoledronic resulted in a $17 \%$ and $26.5 \%$ reduction of prostate epithelial colony size in non-malignant and malignant co-cultures respectively. The reduction in colony size increased with increasing concentrations of Zoledronic acid resulting in reductions of $51 \%$ and $66.5 \%$ at $40 \mu \mathrm{M}$ in non-malignant and malignant cocultures respectively. Typical colonies formed in the varying concentrations of Zoledronic acid and at $40 \mu \mathrm{M}$ concentrations of Pamidronate, Clodronate or EDTA are shown in Fig. 5c.

\subsection{Effect of zoledronic acid on the cytokine milieu in prostate epithelial/bone marrow co-cultures}

We have previously shown that MMP-1 and MMP-7 are necessary for malignant prostate epithelial cells to invade through the bone marrow stroma and form colonies in bone marrow stroma co-culture. Blocking MMP activity resulted in reduction in colony size [8]. To assess the effect of Zoledronic acid had on specific
MMP's, supernatants were collected from malignant primary prostate epithelial cells co-cultured with bone marrow stroma for $72 \mathrm{hr}$ in the presence of $100 \mu \mathrm{M}$ EDTA or bisphosphonate and the concentration of MMP-1 and MMP-7 determined by ELISA. We also determined the expression of the MMP inhibitors TIMP-1 and TIMP-2 and the cytokines TGF $\beta$, VEGF and GM-CSF (Table 2). The concentration of each enzyme and cytokine was then compared to the media only control to determine the percentage up or down regulation resulting from $100 \mu \mathrm{M}$ drug treatment (Table 2).

Unlike EDTA all the bisphosphonates induced increased expression of MMP-1 with Pamidronate and Clodronate inducing approximately double the amount of MMP-1 (121\% and 94\% respectively). However, only Zoledronic acid had a marked effect on the level of MMP-7 expression, reducing levels of MMP-7 in the media by $44 \%$ in respect to the no drug controls. The levels of TIMP-1 were reduced by drug treatment as were the levels of TIMP-2 after EDTA and Pamidronate treatment. Unlike Pamidronate, 
Table 2

Effect of bisphosphonate treatment on the cytokine milieu of prostate epithelial/bone marrow co-cultures

\begin{tabular}{|c|c|c|c|c|c|c|c|c|}
\hline & Concentr & upernatan & $\left.1^{-1}\right)$ and $p e$ & differen & ntrol & & & \\
\hline & EDTA & & Zoledonic & & Pamidronate & & Clodronat & \\
\hline MMP-1 & - & $(-)$ & 0.316 & $(+63)$ & 0.427 & $(+121)$ & 0.376 & $(+94)$ \\
\hline MMP-7 & 1.191 & $(+3)$ & 0.642 & $(-44)$ & 1.082 & $(-6)$ & 1.157 & $(-)$ \\
\hline TIMP-1 & 398.3 & $(-16)$ & 346.9 & $(-27)$ & 411 & $(-13.3)$ & 433.6 & $(-8.4)$ \\
\hline TIMP-2 & 0.061 & $(-10.9)$ & 0.534 & $(+871)$ & 0.04 & $(-27)$ & 0.088 & $(+60)$ \\
\hline TGF $\beta$ & 720.9 & $(-37)$ & 1319.7 & $(+13)$ & 485 & $(-58)$ & 434.6 & $(-97)$ \\
\hline VEGF & 2.137 & $(-7)$ & 2.07 & $(-17)$ & 2.17 & $(-5)$ & 2.14 & $(-7)$ \\
\hline GM-CSF & 89.3 & $(-9.8)$ & 56.07 & $(-43)$ & 84.42 & (14.8) & 86.9 & $(-12.3)$ \\
\hline
\end{tabular}

The concentration of enzymes and cytokines in the supernatants from malignant primary prostate epithelial cells co-cultured with bone marrow stroma in the presence of $100 \mu \mathrm{M}$ bisphosphonate or EDTA for $72 \mathrm{hr}$ was determined by ELISA. The percentage difference to untreated co-cultures in amounts of secreted enzyme/cytokine is shown in parentheses.

Clodronate treatment resulted in marked increase in TIMP-2 expression, 60\% greater than background. Zoledronic acid induced the greatest levels of TIMP2 expression of all treatments, with expression of $867 \%$ $(0.534 \mathrm{ng} / \mathrm{ml})$ above untreated control levels. All drug treatments reduced the levels of VEGF, GMCSF and except for Zoledronic acid TGF- $\beta$, in which an increase in expression was observed. In both VEGF and GMCSF expression Zoledronic acid treatment resulted in the greatest reduction in expression (17\% and $43 \%$ respectively).

\section{Discussion}

The geminal bisphosphonates are a relatively new class of drugs which have been developed as agents to decrease bone resorption in benign and malignant disease. However, more recent work has documented anti-cancer properties in the more potent of these, notably, inhibitory effects on cancer cell proliferation [26] and promotion of apoptosis [27]. This effect has been noted recently in prostate cancer cell lines in vitro. Studies have shown that various bisphosphonates, in particular Zoledronic acid, have been shown to inhibit prostate cellular growth $[18,19]$ through mechanisms thought to be related to promotion of apoptosis via Ras prenylation $[17,19]$.

In addition, there is evidence suggesting that there is added potential for the more potent Nitrogen containing bisphosphonates to be used as anti-metastatic agents. A report by Boissier et al. [12] has suggested that the addition of Zoledronic acid to prostate cancer cell lines in vitro results in a decrease in the capacity of these cells to bind at potential metastatic sites [12,26]. Such a property would have considerable potential as an important means of inhibiting metastatic spread. In this reported series of experiments we have used established models of metastatic binding and growth to study the behaviour of isolated human prostate cells and cell lines in human bone marrow endothelium and bone marrow stroma to determine the extent of binding, migration and growth inhibition of prostate cancer cells by bisphosphonates. This done, we have gone on to explore some of the mechanisms by which this process is inhibited.

The first step in the development of a metastatic deposit is at the point where the malignant cell binds to the endothelial surface at the metastatic site (e.g. bone marrow). Once the cell migrates through this layer it then has to bind to the stroma below (e.g. bone marrow stroma) before it can become established and grow. In this study, by contrast with other groups $[12,26]$ we did not find an inhibition of the binding of prostate epithelial cells to the bone marrow. We believe that this is due to differences in methodology in the previous studies. In these experiments, cells were seeded and left in vitro for a $24 \mathrm{hr}$ period before cell numbers were recorded. In previous work [7] we have shown that the process of cell-endothelial and cell - stromal binding is much more rapid than this, with the majority of cells being bound within 30 minutes and virtually all of them being bound within 60 minutes. The experiments described in this report are therefore much more representative of what actually happens in relation to epithelial/endothelial cell binding in vivo. With regard to the two previous studies relating to the "inhibition of binding", we feel that the reduced cell count observed in these experiments by contrast with our report may have been a consequence of inhibition of proliferation of the bound cells by the bisphosphonate once the initial binding step had taken place on unmineralised and mineralised osteoblastic extra-cellular matrices [12] or plastic [26] rather than a specific inhibition of binding per se.

Our results did confirm that Zoledronic acid had a significant inhibitory effect on the ability of cells to 
migrate. Such effects were not seen with the concentrations of Clodronate or Pamidronate used within this study. Studies by Boissier et al. have shown that Clodronate can inhibit prostate epithelial invasion but it is 50 million fold less potent than Zoledronic acid [13]. The likely cause of this is because Clodronate is not an amino bisphosphonate and as such, it has no effect as an inhibitor of the Mevalonate pathway [28]. The differential effect between Pamidronate and Zoledronic acid is likely to be a consequence of the difference in potency of the two compounds: Zoledronic acid is the most potent of the aminobisphosphonates [29].

Regarding cellular migration, one hypothesis we tested was that this was a consequence of changes in the permeability of the endothelial barrier consequent upon drug treatment. From our current work we know that prostate epithelial cells impinge on and migrate through the endothelial "tight junctions". EDTA decreases the integrity of the endothelial layer by affecting the tight junction binding, thus increasing its permeability [30]. This is shown by the results in Table 1. The less potent drugs, Clodronate and Pamidronate, had no effect on the permeability of the barrier. This was also true of Zoledronic acid at conventional levels below $100 \mu \mathrm{M}$, although, when the levels of the latter were stepped up to $100 \mu \mathrm{M}$ there was a decrease in the permeability, possibly arising as a consequence of the "tightening" of the tight cell junctions in the endothelial mono-layer. It is unlikely therefore that changes in the pattern of cell migration arise as a consequence of changes in the structural integrity of the endothelial barrier itself. However, in the co-culture invasion assays both with matrigel alone and especially with matrigel and a bone marrow endothelial layer there was a marked inhibition of cell invasion with Zoledronic acid at concentrations well below those required to "tighten" the endothelial barrier. This effect is almost certainly a consequence of changes in epithelial cell motility and/or the ability of epithelial cells to produce enzymes to degrade the basement membrane.

Specific measurements of motility were not undertaken in this series of experiments although the importance of this phenomenon in metastasis formation is well documented $[21,31]$ and there is ample proof of principle in the scientific literature with regard to prostate and other tumours. Cell motility and migration is linked integrally to Ras and the GTP binding proteins Rho, Rac and Rab. These are important for many cellular functions including cytoskeletal assembly, intra-cellular signalling and cellular motility [32]. The nitrogen containing bisphosphonates such as Zole- dronic acid inhibit the Mevalonate cellular signalling pathway [28] due to an inhibition of the enzyme pyrophosphate synthase $[33,34]$. This decreases the formation of the isoprenoid lipids, Farnesyl and Geranylgeranyl pyrophosphate, which are required for the post-translational prenylation (transfer of fatty acid chains) of proteins including Ras, Rac, Rho and Rab. Their inhibition by a drug such as Zoledronic acid would therefore inhibit motility critical to cell migration and metastasis. In an elegant series of experiments [14] it has been shown that the invasive properties of the breast cancer cell line MDA-MB-231 through matrigel are inhibited by Zoledronic acid at low concentrations $(1 \mu \mathrm{M})$ and that this process is linked to inhibition of the RhoA protein. The authors in this study showed that the effect at this concentration in these cells is related specifically to inhibition of geranylgeranylation and that this results in a decrease in the translocation of RhoA from the cytoplasm to the cell membrane. This interference with the critical RhoA signalling mechanism may also be occurring in prostate cancer cells although this was not measured specifically in the experiments reported here.

Another factor observed in this study was the effect of Zoledronic acid on the levels of the degradative enzymes, matrix metalloproteinases (MMPs) and their inhibitory controllers, Tissue Inhibitors of Matrix Metalloproteinase (TIMPs). There are currently 24 different MMPs described in the literature [35] and the rational for selecting MMPs 1 and 7 in this study was the known influence of these two forms of the enzyme on prostate cancer metastatic development [8]. Our results here showed that Zoledronic acid caused a significant reduction in MMP-7 levels and an even greater proportionate increase in the levels of its inhibitor TIMP-2. Denoyelle et al. [14] did not see an increase in MMP-2 and -9 levels at the $1 \mu \mathrm{M}$ Zoledronic acid concentrations and on this basis argue that MMP degradation is not a factor in the inhibition of cellular migration. This is not a hypothesis which we would support. Our study shows that there was a clearly measurable change in the levels of MMP-7 and TIMP-2 and in particular, to changes in the balance of MMP and TIMP-2 levels (see below), following Zoledronic acid incubation. It is therefore likely that this measured phenomenon is one of the major reasons why the migration of prostate cancer cellular migration across the endothelial barrier is reduced. The difference between the results in the two studies might be accounted for by a number of reasons. Firstly, the cells under test are prostate rather than breast, secondly, the bisphosphonate concentrations at which MMP changes were measured are higher in our study $(40 \mu \mathrm{M}$ vs. 
$1 \mu \mathrm{M})$, but still potentially within a therapeutic range, and thirdly, there was an endothelial barrier in addition to matrigel in one arm of our invasion experiments, something which is more representative of the situation occurring in vivo.

The mechanism of MMP inhibition remains a matter of speculation although it is possible that this too is linked to the primary inhibition of the Mevalonate pathway and Ras inactivation. Inhibition of the Ras/ Rho/MAP Kinase pathway, linked through mevalonate pathway control, is known to inhibit MMP production in some tumour cell types [36] and inhibition of Ras in vitro will also block the production of MMPs [37]. Denoyelle et al. [14] propose that the action of Zoledronic acid is through the geranylgeranylation route and not through farnesylation. By this hypothesis they propose that the action of Zoledronic acid is not through Ras but solely through the RhoA mechanism. Whilst these observations may be true at the lower concentrations of Zoledronic acid $(1 \mu \mathrm{M})$ used in their experiments on breast cancer cells, they may not be at the higher concentrations such as the $40 \mu \mathrm{M}$ used in this study. We would argue that on the basis of our results there is a definite change measurable in the MMP/TIMP levels and that this may theoretically be linked directly through Ras inhibition.

The inhibitory effect on prostate cancer cellular proliferation is demonstrated clearly at concentrations which should be achievable in a therapeutic setting and in addition, the differential effect of the amino and non-amino bisphosphonates has been demonstrated once more. We also studied the effects on the haematological system. The rationale for this was the small but non-significant fall in haemoglobin levels observed when Zoledronic acid is administered to prostate cancer patients in the clinical setting [5]. We used the Mix assay [22] to look at the effect on haematological precursors and to identify a "therapeutic window". Studies to date have differed widely in the estimation of the concentration of bisphosphonate at tissue interfaces in vivo. They range from $800 \mu \mathrm{M}$ at the osteoclast/bone interface [38] to $1 \mu \mathrm{M}$ in microscopic tumour nests in bone [39]. We found that Zoledronic acid was by far the most potent agent tested in relation to its effect on bipotent haematological progenitors. However, these effects only occurred at the concentrations of $>50 \mu \mathrm{M}$. At concentrations below this there was still some effect but it was much reduced. There does therefore seem to be a therapeutic window at the $40 \mu \mathrm{M}$ level, a concentration at which anti-proliferative and anti-migration effects were observed in relation to Zoledronic acid.

Our experiments support recently published work regarding the anti-proliferative effect of Zoledronic acid in prostate [19] and other epithelial cancers [40] and confirms its superior efficacy by comparison with other amino and non-amino bisphosphonates [18], being 3 fold more potent than Pamidronate [26]. The likely anti-proliferative mechanism is the promotion of apoptosis, as has been discussed previously $[17,19]$. However, the observed changes in MMP-7 and TIMP-2 seen in this study may add an extra dimension to the discussion as to why proliferation is reduced. It has been shown that activated MMP-7 is fundamental to the ability of prostate cancer cells to proliferate in bone marrow stroma in vitro and that MMP-7 is widely distributed in human prostatic bone metastases [8]. Gene expression analysis have shown that whilst the levels of MMP-7 expression does not differ between normal and metastatic prostate tissue, TIMP-2 is down regulated in metastatic disease [41]. This MMP/TIMP-2 imbalance favours expression of active MMPs leading to degradation of the extracellular matrixes and subsequent tumour invasion and metastases. Such an imbalance has been detected in hepatocellular carcinoma in which the levels of MMP-2 remain statistically similar between patients with/without metastatic disease. However, the levels of serum TIMP-2 were significantly reduced in patients with metastatic disease [42]. It is therefore possible that the increase in TIMP-2 induced by Zoledronic acid results in a change in TIMP/MMP balance, favouring a non metastatic phenotype, may have an additional contribution to the anti-proliferative effects of this drug, as well as to its anti-invasive properties.

In conclusion, our results show that although Zoledronic acid has no demonstrable effect on epithelial/ endothelial binding or on the structural integrity of the endothelial barrier in terms of its general permeability, it has a significant inhibitory action on cell migration across the bone marrow endothelial barrier. This inhibition is at least partly related to changes in matrixmetalloproteinase levels and their tissue inhibitors, particularly decreases in MMP-7 and increases in TIMP-2 levels. These findings lend weight to the proposal that this compound has significant potential for use as an anti-metastatic agent. Thus, beyond its efficacy in the treatment of bone metastases, Zoledronic acid might also be effective in the prevention of bone metastases from prostate cancer, as already shown in animal models [27]. We have also confirmed the work of others that the Aminobisphosphonates have significant anti-proliferative activity against prostate cancer cell lines but additionally, they are effective against primary human prostate cancer cells in vitro in co-culture with human bone marrow. 
The anti-proliferative effects of Zoledronic acid also inhibit haematological precursors but this seems to be at a drug concentration level above that which affects epithelial proliferation and migration.

\section{References}

[1] Waltregny D, Castronovo V. Recent advances in prostate cancer metastasis. Tumori 1996;82:193-204.

[2] McIntyre IG, Spreckley K, Clarke RB, Anderson E, Clarke NW, George NJ. Optimization of the reverse transcriptase polymerase chain reaction for the detection of circulating prostate cells. Br J Cancer 2000;83:992-7.

[3] Dodds PR, Caride VJ, Lytton B. The role of vertebral veins in the dissemination of prostatic carcinoma. J Urol 1981;126:753-5.

[4] Carlin BI, Andriole GL. The natural history, skeletal complications, and management of bone metastases in patients with prostate carcinoma. Cancer 2000;88:2989-94.

[5] Saad F, Gleason DM, Murray R, Tchekmedyian S, Venner P, Lacombe L, et al. A randomized, placebo-controlled trial of zoledronic acid in patients with hormone-refractory metastatic prostate carcinoma. J Natl Cancer Inst 2002;94:1458-68.

[6] George NJ. Conservative management of prostate cancer. Lancet $1988 ; 1$.

[7] Scott LJ, Clarke NW, George NJ, Shanks JH, Testa NG, Lang SH. Interactions of human prostatic epithelial cells with bone marrow endothelium: binding and invasion. Br J Cancer 2001;84:1417-23.

[8] Hart CA, Scott LJ, Bagley S, Bryden AA, Clarke NW, Lang SH. Role of proteolytic enzymes in human prostate bone metastasis formation: in vivo and in vitro studies. Br J Cancer 2002;86:1136-42.

[9] Lipton A. Bisphosphonates and breast carcinoma: present and future. Cancer 2000;88:3033-7.

[10] Clarke NW, McClure J, George NJ. Disodium pamidronate identifies differential osteoclastic bone resorption in metastatic prostate cancer. Br J Urol 1992;69:64-70.

[11] Clarke NW, Holbrook IB, McClure J, George NJ. Osteoclast inhibition by pamidronate in metastatic prostate cancer: a preliminary study. Br J Cancer 1991;63:420-3.

[12] Boissier S, Magnetto S, Frappart L, Cuzin B, Ebetino FH, Delmas $\mathrm{PD}$, et al. Bisphosphonates inhibit prostate and breast carcinoma cell adhesion to unmineralized and mineralized bone extracellular matrices. Cancer Res 1997;57:3890-4.

[13] Boissier S, Ferreras M, Peyruchaud O, Magnetto S, Ebetino FH, Colombel $\mathrm{M}$, et al. Bisphosphonates inhibit breast and prostate carcinoma cell invasion, an early event in the formation of bone metastases. Cancer Res 2000;60:2949-54.

[14] Denoyelle C, Hong L, Vannier JP, Soria J, Soria C. New insights into the actions of bisphosphonate zoledronic acid in breast cancer cells by dual RhoA-dependent and -independent effects. Br J Cancer 2003;88:1631-40.

[15] Senaratne SG, Colston KW. Direct effects of bisphosphonates on breast cancer cells. Breast Cancer Res 2002;4:18-23.

[16] Senaratne SG, Mansi JL, Colston KW. The bisphosphonate zoledronic acid impairs membrane localisation and induces cytochrome c release in breast cancer cells. Br J Cancer 2002;87:1340.

[17] Senaratne SG, Mansi JL, Colston KW. The bisphosphonate zoledronic acid impairs Ras membrane [correction of impairs membrane] localisation and induces cytochrome $\mathrm{c}$ release in breast cancer cells. Br J Cancer 2002;86:1479-86.

[18] Dumon JC, Journé F, Kheddoumi N, Lagneaux L, Boddy JJ. Cytostatic and apoptotic effects of bisphosphonates on prostate cancer cells. Eur Urol 2004;45:521-9.

[19] Oades GM, Senaratne SG, Clarke IA, Kirby RS, Colston KW. Nitrogen containing bisphosphonates induce apoptosis and inhibit

\section{Acknowledgements}

Supported by a scientific grant from Novartis Pharma AG, Basel, Switzerland.

the mevalonate pathway, impairing Ras membrane localization in prostate cancer cells. J Urol 2003;170:246-52.

[20] Virtanen SS, Vaananen HK, Harkonen PL, Lakkakorpi PT Alendronate inhibits invasion of PC-3 prostate cancer cells by affecting the mevalonate pathway. Cancer Res 2002;62:2708-14.

[21] Lang SH, Clarke NW, George NJ, Allen TD, Testa NG. Interaction of prostate epithelial cells from benign and malignant tumor tissue with bone-marrow stroma. Prostate 1998:34:203-13.

[22] Coutinho LH, Gilleece MH, de Wynter E, Will A, Testa NG. Clonal and long-term cultures using human bone marrow. In: Testa NG, Molineux G, editors. Haemopoiesis: a practical approach. Oxford: Oxford University Press; 1993. p. 75-106.

[23] Kaighn ME, Narayan KS, Ohnuki Y, Lechner JF, Jones LW. Establishment and characterization of a human prostatic carcinoma cell line (PC-3). Invest Urol 1979;17:16-23.

[24] Almeida-Porada G, Ascensao JL. Isolation, characterization, and biologic features of bone marrow endothelial cells. J Lab Clin Med 1996;128:399-407.

[25] Watts ME, Woodcock M. Flavone acetic acid induced changes in human endothelial permeability: potentiation by tumour-conditioned medium. Eur J Cancer 1992;10:1628-32.

[26] Lee MV, Fong EM, Singer FR, Guenette RS. Bisphosphonate treatment inhibits the growth of prostate cancer cells. Cancer Res 2001;61:2602-8.

[27] Corey E, Brown LG, Quinn JE, Poot M, Roudier MP, Higano CS, et al. Zoledronic acid exhibits inhibitory effects on osteoblastic and osteolytic metastases of prostate cancer. Clin Cancer Res 2003;9:295-306.

[28] Luckman SP, Coxon FP, Ebetino FH, Russell RG, Rogers MJ. Heterocycle-containing bisphosphonates cause apoptosis and inhibit bone resorption by preventing protein prenylation: evidence from structure-activity relationships in J774 macrophages. J Bone Miner Res 1998;13:1668-78.

[29] Green JR. Chemical and biological prerequisites for novel bisphosphonate molecules: results of comparative preclinical studies. Semin Oncol 2001;28:4-10

[30] Kartenbeck J, Schmelz M, Franke WW, Geiger B. Endocytosis of junctional cadherins in bovine kidney epithelial (MDBK) cells cultured in low Ca2+ ion medium. J Cell Biol 1991;113:881-92.

[31] Lang SH, Clarke NW, George NJ, Testa NG. Scatter factor influences the formation of prostate epithelial cell colonies on bone marrow stroma in vitro. Clin Exp Metastasis 1999;17:333-40.

[32] Oxford G, Theodorescu D. Ras superfamily monomeric G proteins in carcinoma cell motility. Cancer Lett 2003;189:117-28.

[33] van Beek E, Pieterman E, Cohen L, Lowik C, Papapoulos S. Farnesyl pyrophosphate synthase is the molecular target of nitrogen-containing bisphosphonates. Biochem Biophys Res Commun 1999;264:108-11.

[34] Bergstrom JD, Bostedor RG, Masarachia PJ, Reszka AA, Rodan G. Alendronate is a specific, nanomolar inhibitor of farnesyl diphosphate synthase. Arch Biochem Biophys 2000;373:231-41.

[35] Overall CM, Lopez-Otin C. Strategies for MMP inhibition in cancer: innovations for the post-trial era. Nat Rev Cancer 2002;2:657-72.

[36] Shin M, Yan C, Boyd D. An inhibitor of c-jun aminoterminal kinase (SP600125) represses c-Jun activation, DNA-binding and PMAinducible 92-kDa type IV collagenase expression. Biochim Biophys Acta 2002;8:311-6.

[37] Futamura M, Kamiya S, Tsukamoto M, Hirano A, Monden Y, Arakawa $\mathrm{H}$, et al. Malolactomycin D, a potent inhibitor of 
transcription controlled by the Ras responsive element, inhibits Rasmediated transformation activity with suppression of MMP-1 and MMP-9 in NIH3T3 cells. Oncogene 2001;20:6724-30.

[38] Sato M, Grasser W, Endo N, Akins R, Simmons H, Thompson DD, et al. Bisphosphonate action. Alendronate localization in rat bone and effects on osteoclast ultrastructure. J Clin Invest 1991;88:2095105.

[39] Usui T, Tanaka S, Sonoda T, Ozawa Y, Teramura K, Nakamura E, et al. Drug disposition of incadronate, a new bisphosphonate, in rats with bone metastases. Xenobiotica 1997;27:479-87.

\section{Editorial Comment}

\section{A. Heidenreich, Cologne, Germany}

axel.heidenreich@uk-koeln.de

The clinical application of bisphosphonates (BP) besides a mere palliative indication for pain management [1] has regained new interest since the positive results of zoledronic acid to not only reduce the frequency of skeletal related events but also to prolong to double the interval until skeletal related events develop [2].

Montague et al. are to be congratulated to a very sophisticated in-vitro study on the potential properties of bisphosphonates (BP) to inhibit invasion and proliferation of prostate cancer cells in the bone marrow which might have some significant impact on the future strategies to manage high risk prostate cancer (PCA).

The authors identified several mechanisms shedding some more light on the binding, migration and proliferation mechanisms of PCA cells to the human bone marrow stroma which, however, need some more explanation with regard to the translation of these data into daily clinical practice.

The process of bone metastases development is very complex and it is summarized very simply; the interested reader might study the more sophisticated review of Mundy [3]. Once PCA cells have detached from their intraprostatic primary and circulate in the peripheral blood, they very rapidly bind to the endothelium of the bone marrow (BM) by some osteogenic properties. Migration through the BM followed by coalescence and proliferation are some other important prerequisites for the formation of metastatic colonies. Proliferation, however, is the result of several autocrine and paracrine mechanisms triggered by the expression of several growth factors, direct stimulation of osteoclasts and osteoblasts resulting in the well known devastating skeletal morbidity of advanced PCA.

Using various in-vitro assays to examine the inhibiting properties of zoledronic acid (ZA) compared to pamidronate and clodronate with regard to inhibition of binding, penetration, invasion, and proliferation of
[40] Jagdev SP, Coleman RE, Shipman CM, Rostami HA, Croucher PI. The bisphosphonate, zoledronic acid, induces apoptosis of breast cancer cells: evidence for synergy with paclitaxel. Br J Cancer 2001;84:1126-34.

[41] Dhanasekaran SM, Barrette TR, Ghosh D, Shah R, Varambally S, Kurachi K, et al. Delineation of prognostic biomarkers in prostate cancer. Nature 2001;412:822-6.

[42] Giannelli G, Bergamini C, Marinosci F, Fransvea E, Quaranta M, Lupo L, et al. Clinical role of MMP-2/TIMP-2 imbalance in hepatocellular carcinoma. Int J Cancer 2002;97:425-31.

PCA cells, Montague et al. found interesting results with potential future clinical impact.

Although none of the BP significantly inhibited binding of PC-3 cells to the BM endothelial, ZA significantly reduced the capability of PC-3 cells to invade the BM endothelial most probably due to the reduction of degradation enzymes such as matrix metalloproteinases (MMP) and their controlling TIMP. Similar results have already been described by others examining the effects of alendronate and ibandronate $[4,5]$. In addition, both, pamidronate and ZA reduced the formation of metastatic colonies with a more pronounced effect for ZA at dose levels which can be achieved under clinical conditions.

Translating these experiments into an in-vivo model could reproduce the data [6-8]. Treatment of animals with $\mathrm{ZA}$ and ibandronate prior to the inoculation of PCA cells into the bone marrow or the systemic circulation resulted in a significant reduction of metastatic colonies and a significant inhibition of the synthesis of MMPs, TGF- $\beta$, collagen- 1 and osteoclast activity. Treatment following the inoculation of PCA cells in the BM had no preventive effect on the formation of metastases.

In addition, BP exert a synergistic effect with some cytotoxcic agents such has the taxane paclitaxel. Combination of alendronate and paclitaxel resulted in a significant reduction of the number of bone metastases and visceral metastases as well as a significant prolongation of survival in animals $[7,8]$.

In conclusion, the in-vitro data presented by Montague et al. and others in combination with the published in-vivo data of experimental treatment studies in SCID mice underline the potential properties of the new nitrogen-containing BP in the early management of high risk PCA following local therapy with curative intent. Currently, two prospective randomized clinical trials are under way to examine the preventive effects of zoledronic acid and ibandronate. The first trial supported by the EAU compares the clinical efficacy of zoledronate versus placebo in roder to reduce skeletal events in high risk PCA. The second trial supported by the Association of Oncological Urology of 
the German Cancer Society compares the clinical efficacy of adjuvant androgen deprivation versus $A D$ plus oral ibandronate versus $\mathrm{AD}$, oral ibandronate and systemic docetaxel to optimize recurrence-free survival in high risk patients following radical prostatectomy [1].

\section{References}

[1] Heidenreich A. Bisphosphonates in the management of metastatic prostate cancer. Oncology Suppl 2003;1:5-11.

[2] Saad F, Gleason DM, Murray R, Tchekmedyian S, Venner P, Lacombe $\mathrm{L}$, et al. A randomized, placebo-controlled trial of zoledronic acid in patients with hormone-refractory metastatic prostate carcinoma. J Natl Cancer Inst 2002;94:1458-68.
[3] Mundy GR. Metastasis to bone: causes, consequences and therapeutic opportunities. Nature Reviews Cancer 2002;2:584-93.

[4] Stearns ME, Wang M. Alendronate blocks metalloproteinase secretion and bone collagen I release by PC-3 ML cells in SCID mice. Clin Exp Metastases 1998;16:693-702.

[5] Stearns ME. Alendronate blocks TGF- $\beta 1$ stimulated collagen 1 degradation by human PC3-ML cells. Clin Exp Metastasis 1998; 16:332-9.

[6] Biossier S, Ferreras M, Peyruchaud O, Magnetto S, Ebetino FH, Colombel $\mathrm{M}$, et al. Bisphosphonates inhibt breast and prostate carcinoma cell invasion, an early event in the formation of bone metastases. Cancer Res 2000;60:2949-54.

[7] Stearns ME, Wang M. Effects of alendronate and taxol on PC3-ML bone metastases in SCID mice. Invasion Metastasis 1996;16:116-31.

[8] Magnetto S, Boissier S, Delmas PD, Clezardin P. Additive antitumor activities of taxoids in combination with the bisphosphonate ibandronate against invasion and adhesion of human breast carcinoma cells to the bone. Int J Cancer 1999;83:263-9. 